\title{
XEOGRAFÍA DO EIXO ATLÁNTICO E CULTURA TERRITORIAL
}

\author{
Xosé Manuel Souto
}

Sociedade Galega de Xeografía

A xeografía é unha ciencia antiga que pretende analizar os diferentes proxectos de humanización da natureza. Por iso ten un enorme interese en coñecer como se percibe o espazo e como se delimita e apropia o territorio. Xorden así as identidades territoriais, as patrias e as nacións, construídas sobre a vontade e expresión política dun colectivo social.

No caso que nos ocupa tamén existiu un proxecto político abandeirado polos alcaldes das principais cidades de Galicia e norte de Portugal, en especial polos de Porto e Vigo, que no ano 1992 constitúen o Pacto Intermunicipal do Eixo Atlántico, primeiro con trece cidades e logo, no 1997, con dezaoito. O Eixo quixo ser, en palabras dos seus voceiros, unha expresión da Europa dos cidadáns, fronte á Europa das rexións, que tivo o seu gromo na política rexional da Comunidade Europea, logo Unión Europea. Así a antiga Gallaecia é por unha banda un resultado da política europea, pero tamén procura ser a resposta da vontade política dos poderes locais.

\section{O EIXO ATLÁNTICO E A POLÍTICA EUROPEA}

O Eixo Atlántico nace coa vontade de liderar un espazo xeográfico situado no noroeste da Península Ibérica, que ten unha superficie de máis de 50.000 quilómetros cadrados e no que viven máis de 6.000.000 de habitantes. Unha vangarda de cidades para un espazo periférico no conxunto europeo; unha eurorrexión que é periferia na Europa dos quince, pero que muda de situación coa ampliación na

R. Álvarez, F. Dubert, X. Sousa (eds.): Lingua e Territorio Santiago de Compostela: ILG/CCG, 2006, 157-173 ISBN 84-96530-20-5 
Europa dos vinte e sete no período final do primeiro decenio do século XXI, onde se prevé un cambio no sistema e número de instrumentos de financiamento, así como tamén a incidencia que vai ter a chegada de novas rexións de Europa oriental á Unión Europea, pois elas serán as primeiras destinatarias dos fondos de cohesión e das políticas de deslocalización das empresas multinacionais. Xorden novos escenarios que se definen na simplificación dos fondos europeos a dous instrumentos fundamentais: FEDER e FSE.

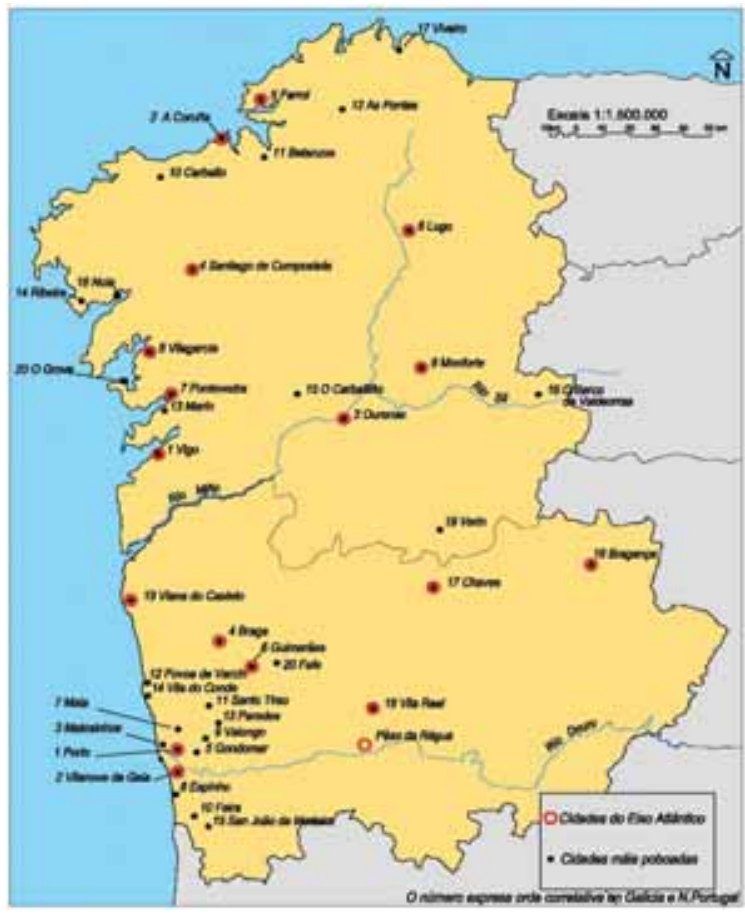

Mapa 1. Cidades do Eixo e cidades máis importantes

A situación periférica da eurorrexión vén determinada por un tipo de emprego que ten escasa relevancia no crecemento do Produto Interior Bruto (PIB), que é inferior ás medias rexistradas en España e Portugal, o que non facilita a converxencia coa Unión Europea, que posúe unha media moi por enriba das rexistradas nos territorios de Galicia e Norte de Portugal (ver cadro 1). E sobre todo, o que subliñan as estatísticas europeas é a distancia que existe 
respecto á innovación tecnolóxica, como se pode comprobar nos índices de solicitudes de patentes. Isto é, atopámonos nunha eurorrexión periférica con problemas de emprego, cunha poboación vella no caso de Galicia e cunha importante presión da poboación nova por atopar emprego no Norte de Portugal. Son retos sociais que se visualizan no territorio e onde as cidades aparecen como áreas de vangarda para intentar mudar esta situación.

\begin{tabular}{|l|r|r|r|r|r|}
\hline & \multicolumn{1}{|c|}{ U.E. (15) } & \multicolumn{1}{c|}{ ESPAÑA } & PORTUGAL & $\begin{array}{r}\text { REXIÓN NORTE } \\
\text { PORTUGAL }\end{array}$ & \multicolumn{1}{c|}{ GALICIA } \\
\hline Poboación & 379.604 .000 & 40.266 .000 & 10.293 .000 & 3.646 .00 & 2.726 .000 \\
\hline Densidade & 117,0 & 79,8 & 112,0 & 171,3 & 92,6 \\
\hline $\begin{array}{l}\text { Crecemento } \\
\text { PIB 1995-2001 }\end{array}$ & 2,5 & 3,7 & 3,5 & 2,6 & 2,8 \\
\hline PIB per cápita & 100 & 84,2 & 70,7 & 56,9 & 66,5 \\
\hline & \multicolumn{7}{|c|}{ Sector de emprego } & \multicolumn{1}{|c|}{} \\
\hline Emprego prim. & 4,0 & 5,9 & 12,4 & 11,4 & 12,9 \\
\hline Emprego secun. & 28,2 & 31,8 & 33,9 & 43,3 & 32,8 \\
\hline Emprego terc. & 67,7 & 62,9 & 53,8 & 45,4 & 54,3 \\
\hline $\begin{array}{l}\text { Solicitudes } \\
\text { patentes/habt. }\end{array}$ & $\begin{array}{r}153,6 \\
\text { por millón }\end{array}$ & $\begin{array}{r}24,1 \\
\text { por millón }\end{array}$ & $\begin{array}{r}4,7 \\
\text { por millón }\end{array}$ & $\begin{array}{r}4,3 \\
\text { por millón }\end{array}$ & $\begin{array}{r}5,0 \\
\text { por millón }\end{array}$ \\
\hline
\end{tabular}

Cadro 1. Principais indicadores rexionais europeos, 2001-2002

Polo mesmo, non podemos falar da Gallaecia sen facer referencia explícita á creación dun marco territorial administrativo no seo da Unión Europea, antes denominada Comunidade Económica Europea, que se ampliou a doce estados no ano 1986 coa incorporación precisamente de España e Portugal. A política rexional das institucións europeas é a responsable directa da creación da eurorrexión e mesmo do pulo que levou a constitución oficial do Pacto Intermunicipal que coñecemos como Eixo Atlántico. Un pacto que se establece nos niveis IV e V das denominadas Unidades Estatísticas Europeas (NUTs) para desenvolver un espazo que forma unha eurorrexión (NUT de nivel II).

A Comunidade de Trabalho Galiza-Norte de Portugal foi constituída o 31 de outubro de 1991, ao abeiro do Acordo Constitutivo elaborado 
á luz da Convención Europea para a Cooperación Transfronteiriza. Os seus obxectivos residen en estimular e coordinar a cooperación entre as terras antigamente separadas polas fronteiras estatais. Unhas finalidades que non poden ser esquecidas nun planeamento estratéxico europeo.

A antiga Gallaecia está circunscrita administrativamente aos territorios de Galicia e rexión Norte de Portugal, que suman pouco máis de 51 milleiros de quilómetros cadrados e case 6,4 millóns de persoas no ano 2001. Resulta así unha eurorrexión cunha paisaxe rural, onde a poboación se vai desprazando desde o emprego agrario ao industrial e de servizos, pois no actual modelo de relacións campo-cidade, consecuencia da dinámica do capitalismo, a agricultura perdeu marxe de operatividade socioeconómica.

Sen dúbida a institucionalización das relacións xeográficas do noroeste peninsular están relacionadas coa evolución política de España e Portugal. En primeiro lugar, a desaparición das ditaduras de SalazarCaetano no ano 1974 e a de Franco no ano 1975. Máis tarde o tratado de Amizade e Colaboración entre España e Portugal no ano 1977, logo a descentralización administrativa en Portugal, coa creación da CCR-N no ano 1979 e a aprobación do Estatuto de Autonomía en Galicia dentro do marco constitucional español de 1978 e finalmente a entrada de España e Portugal no seo das Comunidades Europeas en 1986, logo transformadas en Unión Europea tras o Tratado de Maastricht. Un resumo da evolución histórica da Comunidade de Traballo GalizaNorte de Portugal e mesmo do Eixo Atlántico aparece en Domínguez (2004).

Se no ano 1991 se constituíu a Comunidade de Trabalho GalizaNorte de Portugal, impulsada pola Xunta de Galicia e a Comissão de Coordinação da Região Norte de Portugal, un ano despois produciuse a declaración oficial (abril de 1992 en Porto) da constitución dunha entidade privada: O Eixo Atlántico. Agrupaba a trece cidades-municipios de Galicia e Norte de Portugal ${ }^{1}$, que formalizan o seu pacto o 28 de setembro dese mesmo ano na cidade de Viana do Castelo.

1 Ourense, Lugo, Pontevedra, A Coruña, Santiago de Compostela, Ferrol, Vigo, Porto, Viana do Castelo, Vila Real, Chaves, Braga e Bragança. 
Este convenio de colaboración de trece cidades, logo dezaoito ${ }^{2}$, ten o seu fundamento legal no Convenio Marco de Cooperación Transfronteirizo entre comunidades e autoridades territoriais, publicado no Diario Oficial das Comunidades Europeas do 18 de outubro de 1990. En consecuencia, un mesmo marco legal para favorecer as relacións entre territorios que formaban parte de dous Estados diferentes, pero que formaban parte da Comunidade Europea desde 1986.

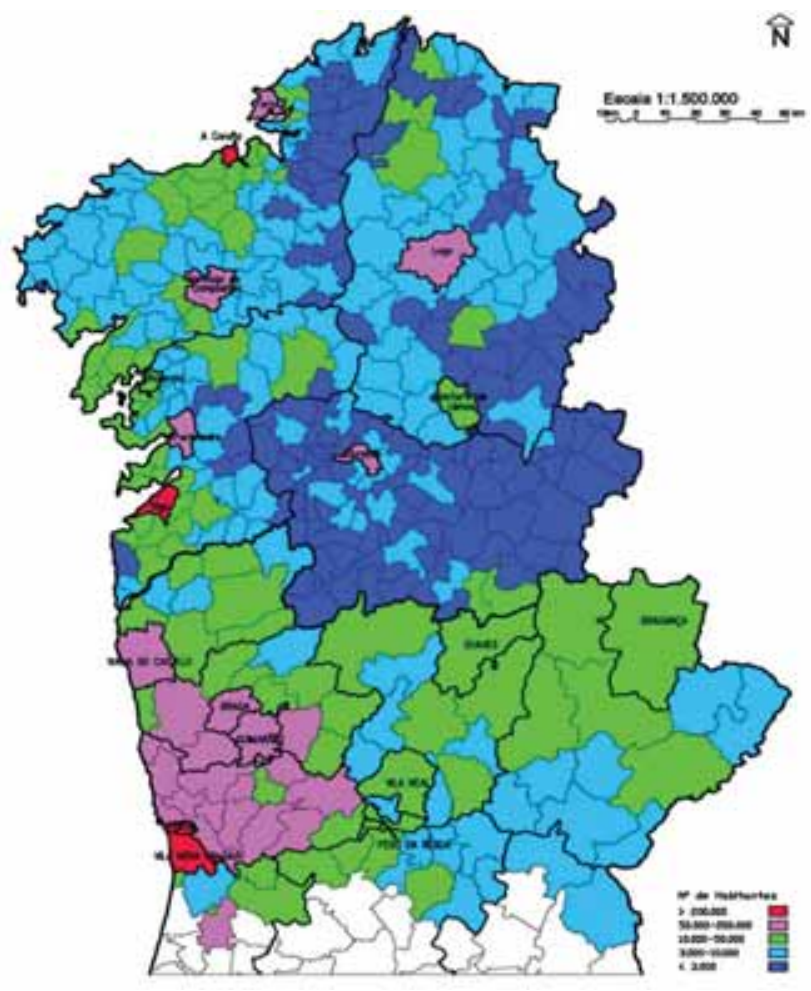

Mapa 2. Poboación absoluta dos concellos da Eurorrexión

Os alicerces deste pacto, que representa a case 2,5 millóns de habitantes nunha concepción restrinxida municipal, aparecen na política

2 O día 24 de xaneiro de 1997 incorpóranse outros cinco municipios: Guimarães, Monforte de Lemos, Peso da Régua, Vila Nova de Gaia e Vilagarcía de Arousa. 
rexional europea e teñen un protagonismo máis grande no momento da ampliación nos primeiros anos deste milenio. $\mathrm{O}$ seu pulo corresponde cunha estratexia rexional europea, do Consello de Rexións e Municipios de Europa (CRME), que deu lugar a un inzamento no número de municipios que estaban irmandados.

\section{UNHA EUROREXIÓN E UN EIXO DE CIDADES}

En consecuencia, a altura de 2004 temos unha eurorrexión de medio centenar de $\mathrm{km}^{2}$ (décima parte da Península Ibérica) que acocha no seu interior máis de seis millóns de habitantes, o que resulta unha densidade media superior á ibérica, cunha paisaxe rural característica. E no cerne desta eurorrexión aparece un pacto intermunicipal que actúa como fulcro da dinámica social e económica desde as cidades. Un pacto que representa unha terceira parte da poboación eurorrexional e cunha superficie que escasamente chega ao $9 \%$ do total. Isto é, un espazo máis denso, economicamente diversificado e dinámico, socialmente contrastado e politicamente máis complexo, pois require do esforzo conxunto e complementario dos dezaoito municipios, unha organización administrativa que nos retrotrae ao primeiro terzo do século XIX para facer fronte aos retos do século XXI.

Unha eurorrexión que se vai alicerzando nun conxunto de novas dinámicas culturais, económicas e sociais, entre as que algunhas son patrocinadas polo Eixo Atlántico, en tanto que persoa xurídica de ámbito supramunicipal, como son os seguintes exemplos:

- Cooperación para o desenvolvemento do cluster automóbil ${ }^{3}$ establecida entre o Centro Tecnolóxico de Automoción de Galicia (CTAG) e o Centro de Excelência e Inovação Industria Automóvel (CEILA) para explorar complementariedades nun sector cun produto global que poderá ter un efecto de fulcro no desenvolvemento eurorrexional ${ }^{4}$.

3 Asinado no Porriño, o 28 de outubro de 2002, no ámbito da Iniciativa Comunitaria INTERREG IIIA.

4 Para lograr este obxectivo o protocolo prevé a creación dun Laboratorio de Impacto asociado ao CTAG; a creación dun Centro de Enxeñería e Desenvolvemento de 


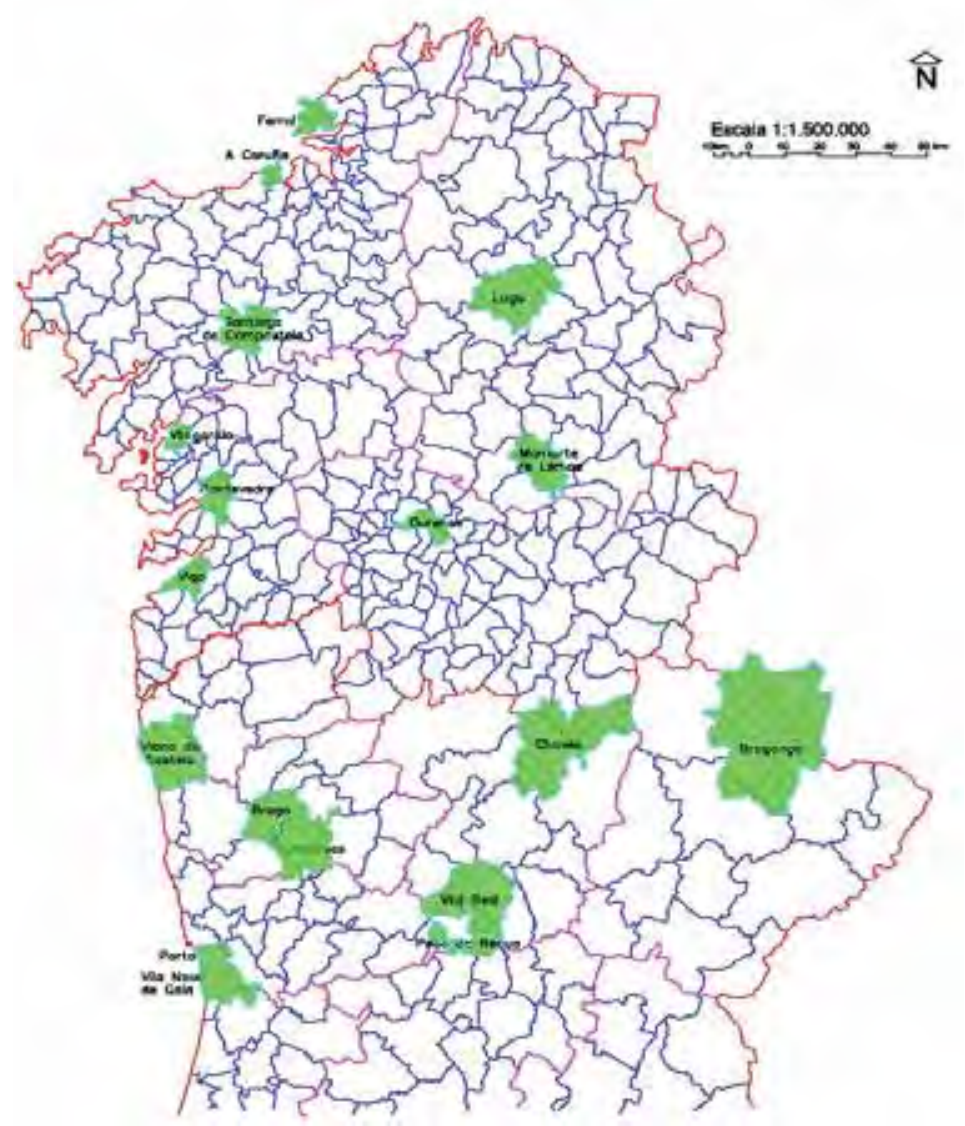

Mapa 3. Concellos do Eixo Atlántico

- Cooperación transfronteiriza para a consolidación de empresas en Galicia e Norte de Portugal (proxecto CONSOLIDA-INTERREG IIIA) establecida entre CEEI Galicia SA; Consorcio da Zona Franca de Vigo; Unrisco Galicia, SCR; Bic Minho; Idite Minho. Proxecto que pretende incrementar a información sobre opor-

Produto (CEDP); a promoción das capacidades tecnolóxicas, organizacionais e humanas das empresas do sector automóbil; a promoción de plataformas conxuntas de formación de recursos humanos; o desenvolvemento e cooperación de ferramentas de e-business entre o Norte de Portugal-Galicia. 
tunidades existentes na eurorrexión, mellorar o coñecemento da realidade económica de Galicia e Norte de Portugal, así como fortalecer as estruturas de xestión de novas empresas e facilitar a asistencia técnica e a implementación de instrumentos para optimizar as competencias profesionais dos cadros directivos.

- Proxecto MRI -Mobilizar a Região para a Inovação (INTERREG IIIA) - para desenvolver un ambiente favorable á innovación eurorrexional a través da promoción da innovación e dos niveis de desenvolvemento tecnolóxico das actividades das empresas e infraestruturas tecnolóxicas rexionais.

- Proxecto CIC-COMMERCE (INTERREg IIIA) para promover a adopción das TIC -Tecnoloxías da Información e da Comunicación- no comercio polo miúdo.

- Proxecto CASTRENOR -Cultura Castrexa no noroeste peninsular (INTERREg IIIA) establecido entre a Universidade do Minho e a Xunta de Galicia-Consellería de Cultura, Comunicación Social e Turismo- con vistas a crear unha rede temática para a promoción da arqueoloxía castrexa, así como potenciar e valorizar o patrimonio arqueolóxico; este proxecto desenvolve unha ruta da cultura castrexa de cariz transfronteirizo e fomenta dinámicas culturais entre o Vale do Ave e Galicia no dominio da valorización do patrimonio arqueolóxico, etc.

- Bienal de Pintura do Eixo Atlántico; premio Eixo Atlántico-La Voz de Galicia de Narrativa Galega e Portuguesa; festivais de teatro e cine do Eixo Atlántico; xogos do Eixo Atlántico; regatas e torneos de balonmán do Eixo Atlántico.

Alén dos exemplos anteriormente referidos, aínda existe a posibilidade mal explorada das colaboracións para o desenvolvemento rural no ámbito da Iniciativa Comunitaria LEADER + (vector 2 - cooperación transnacional) para promoveren conxuntamente diferentes produtos da terra, itinerarios turísticos, gastronomía, utilización das TIC na desconcentración de tarefas e na promoción do teletraballo, etc. Unha panoplia de medidas ás que habería que engadir a candidatura que promoven algunhas institucións locais, culturais e sociais, para que Galicia e Norte de Portugal poidan ser a través da cultura popular un fito relevante como Patrimonio Inmaterial da Humanidade. 
Así, analizar os sistemas urbanos implica necesariamente establecer unha relación entre os territorios do rural e as súas interdependencias coas cidades medias e as respectivas áreas metropolitanas, que se teñen afirmado renunciando á perda de vitalidade do medio rural e do proceso de expansión urbana, en especial na transformación do valor da terra, que pasou de representar un valor de uso a un valor mercantil de carácter inmobiliario.

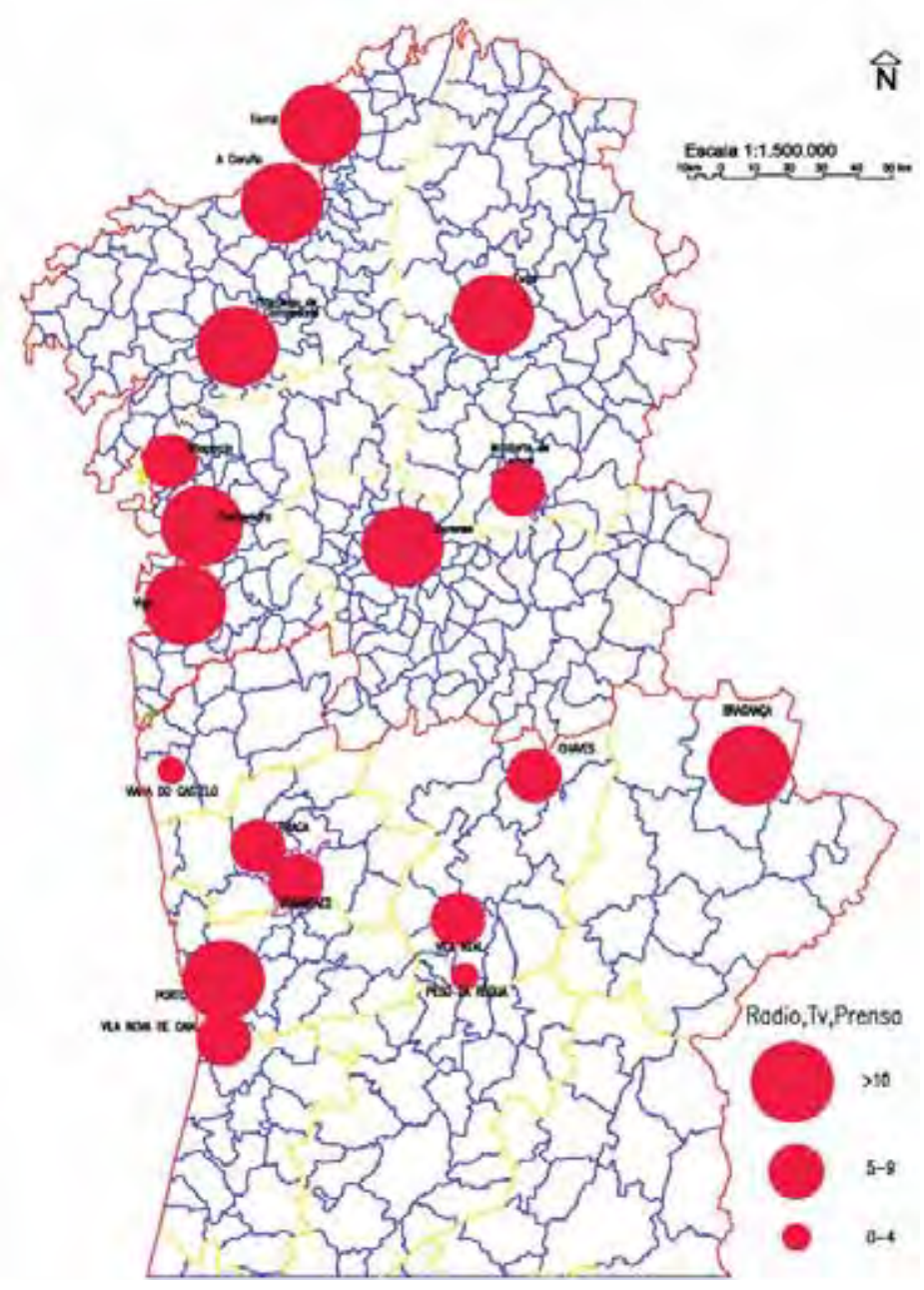

Mapa 4. Medios de comunicación nas cidades do Eixo 


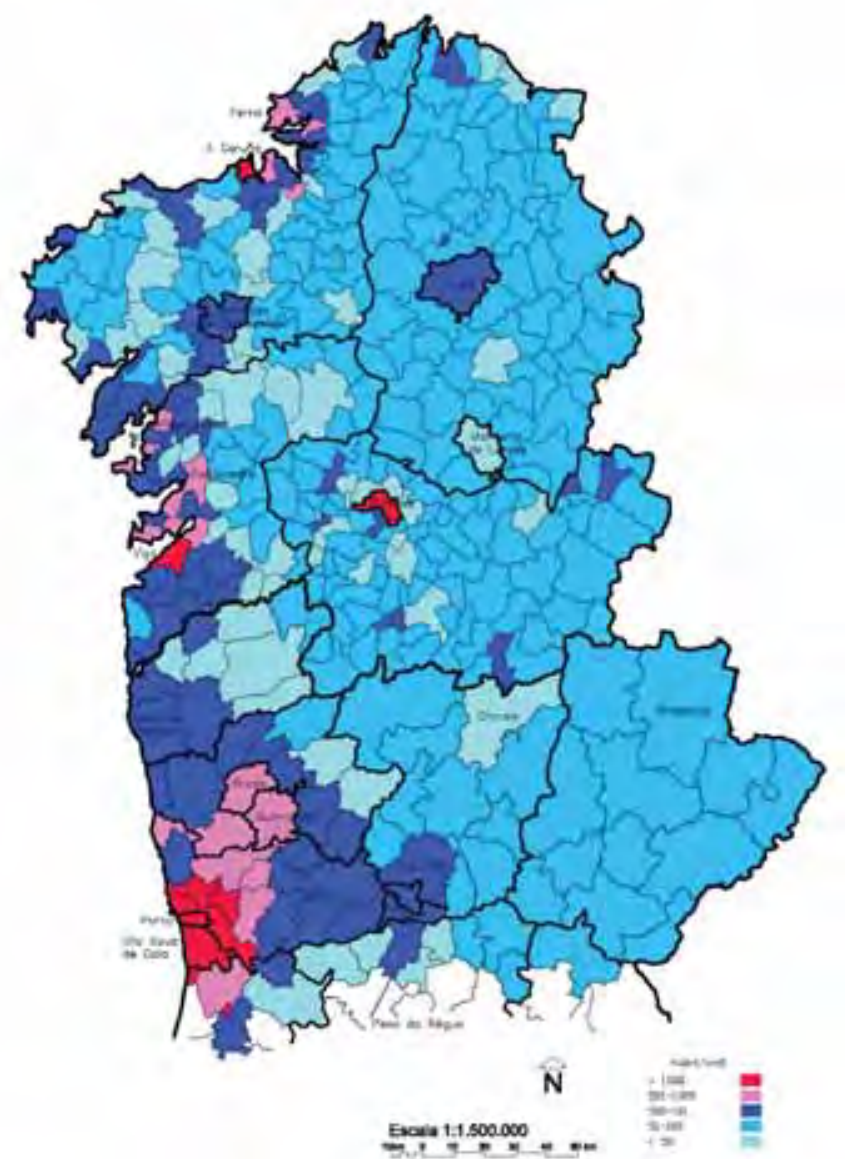

Mapa 5. Densidade de poboación, 2001

O final do século xx e o inicio do século XxI son testemuñas de diversas mutacións territoriais ao nivel do patrimonio natural, cultural e construído, vinculadas a unha reestruturación dos sistemas produtivos, moitas veces marcada polo apátrida, ou dito dunha outra forma, pola globalización, que na súa ansia reprodutiva crea falsas esperanzas e determina unha expansión das cidades con reflexos no poboamento, sobre todo á volta das áreas metropolitanas aparentemente máis dinámicas. E, ao mesmo tempo, xera unhas expectativas de consumo que dan lugar a que o cidadán acabe sendo considerado 
como un cliente. O individuo e o territorio conforman un espazo xeográfico humanizado, onde existen lóxicas contraspostas: chamadas á mobilización pública e forzas sociais que pulan da patrimonialización e privatización do medio.

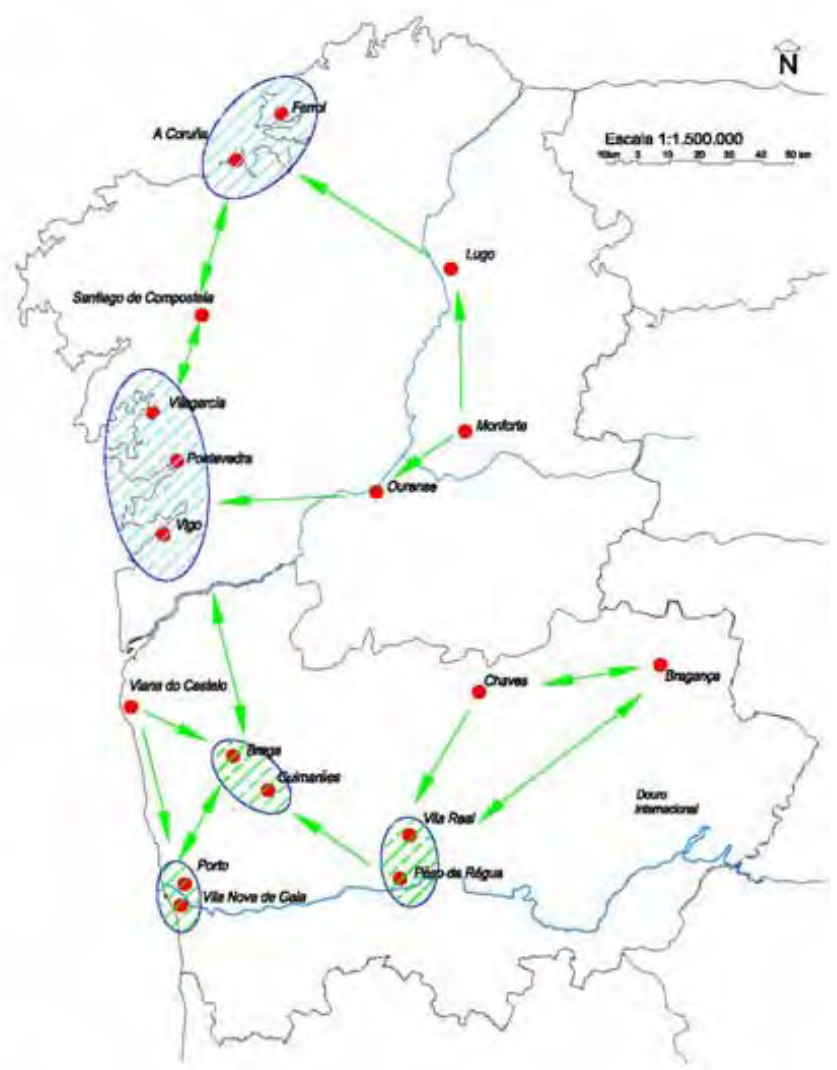

Mapa 6. Relación funcional das cidades do Eixo Atlántico

Simultaneamente existen novos ou vellos territorios que se van tornando menos interesantes, normalmente son os interiores, os rurais máis illados, de onde a fuxida da maior parte da súa poboación nova e produtiva acaba por agravar os síntomas da marxinalidade: envellecemento demográfico, abandono da agricultura, falta de investimento, desemprego, desagregación socioeconómica, descaracterización territorial, falta de esperanza, pobreza, etc. Un proxecto político que 
procura un ordenamento equilibrado entre os medios urbanos e rurais non pode esquecer este fenómeno, que mesmo está presente no interior de certos municipios que teñen unha gran superficie, como nos casos de Lugo, Chaves ou Bragança.

Pensar global e actuar local, unha das armas do desenvolvemento rural, tense mostrado contraproducente sempre que o local non ten capacidade para alimentar o global e algunhas das experiencias ben intencionadas están a acabar no campo das vontades, sobre todo porque o crecemento da falta de interese ou a incapacidade política manifesta a extinción do lume da innovación.

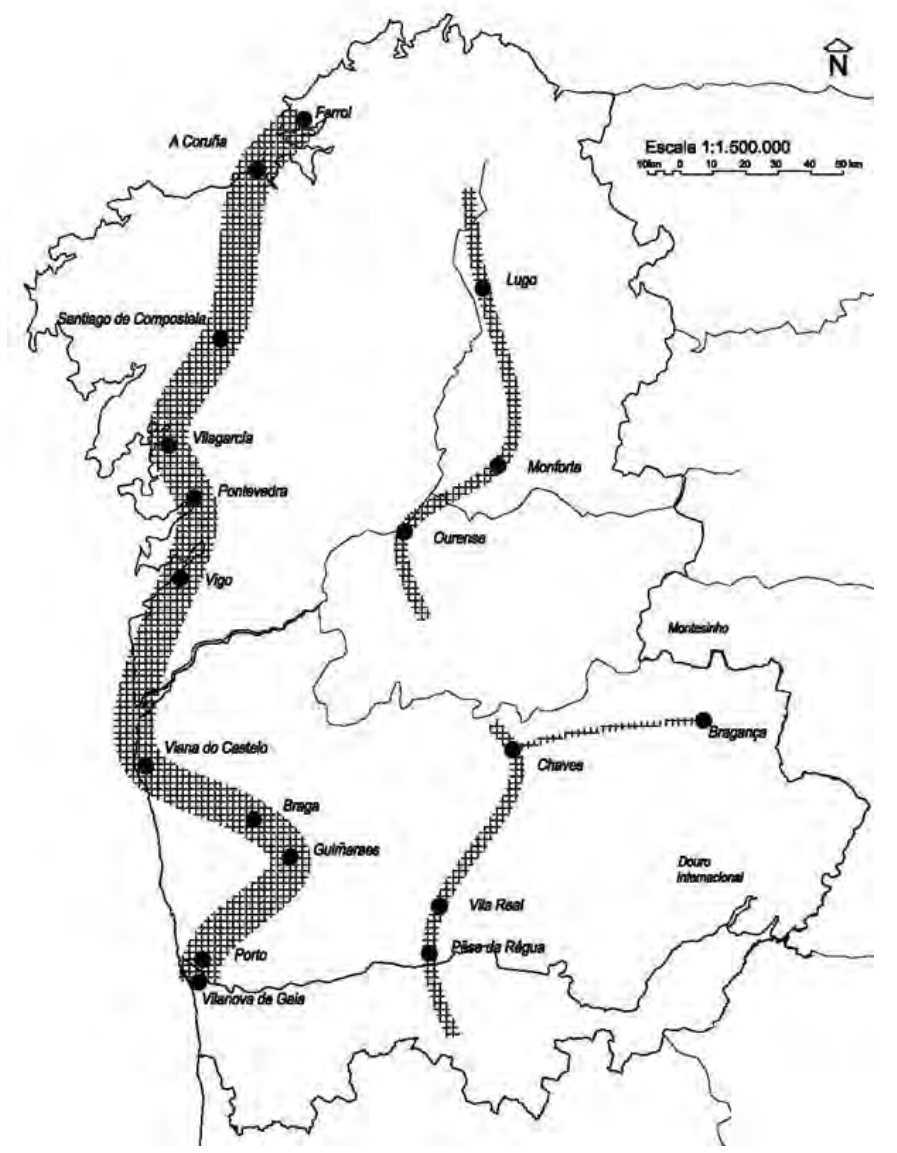

Mapa 7. Sistemas de desenvolvemento no Eixo Atlántico 
As cidades-municipios do século XXI non poden xestionar o territorio desde unha perspectiva excluínte, diferenciando un espazo urbano doutro non urbanizable. Non pode mirar para o espazo circundante como un espazo dos outros, pois isto subliña unha tendencia para acentuar o discurso das discrepancias e para observar o rural na óptica do parente pobre. Un territorio sobre o que se pode experimentar con medidas milagrosas que veñen das cidades: afirmación dos valores e tradicións, eco-desenvolvemento, turismo con diferentes ofertas, novas culturas forestais e agrícolas, novos animais para poboaren os campos, produtos da terra con denominación de orixe, novas institucións de ensino para fixaren alumnos migrantes, etc. Pena é que as experiencias, meritorias na implementación, non teñan na práctica consolidado dinámicas máis afirmativas e que continúe a ser a influencia do urbano a que impón as aproximacións, ou mellor dito as subordinacións.

Deste xeito, entendemos que as cidades-municipios do Eixo Atlántico deben ensarillar sobre o territorio próximo unha política de desenvolvemento territorial acorde coas previsións da Unión Europea, en especial as consagradas no EDEC (Esquema de Desenvolvemento do Espazo Comunitario ${ }^{5}$ ).

Así, debemos atender os seus principios orientadores ${ }^{6}$ :

- o desenvolvemento dun sistema urbano equilibrado e policéntrico e unha nova relación cidade-campo;

- a garantía de paridade de acceso ás infraestruturas e ao saber;

- o desenvolvemento sustentable, a xestión intelixente e a preservación da natureza e do patrimonio cultural.

Pola importancia dos seus presupostos políticos, en especial o ordenamento do territorio, o EDEC pode ser decisivo para alcanzar o obxectivo da cohesión económica e social, polo que merece que se lle preste algunha atención no contexto deste estudo, tanto máis que centra a problemática da sustentabilidade na necesidade de existir un novo modelo de relacionamento entre os territorios, asentado nun diá-

5 O EDEC é un instrumento político para mellorar a cooperación entre as políticas sectoriais comunitarias que teñen un impacto significativo no territorio. Foi aprobado polos ministros responsables do ordenamento do territorio en Potsdam, maio de 1999.

6 SDEC - Schéma de Développement de l'Espace Communautaire, 1999: 11. 
logo interrexional, transrexional e transfronteirizo que contribúa para superar a dicotomía urbano-rural e implementar estruturas territoriais de complementariedade.

\begin{tabular}{|c|c|c|c|c|c|}
\hline MUNICIPIO & $\begin{array}{c}\text { SUPERFICIE } \\
\mathrm{KM}^{2}\end{array}$ & $\begin{array}{c}\text { SUPERFICIE } \\
\%\end{array}$ & $\begin{array}{c}\text { PoB. } \\
\text { Residente }\end{array}$ & $\begin{array}{c}\text { POB. } \\
\text { RESIDENTE \% }\end{array}$ & $\begin{array}{c}\text { DENSIDADE } \\
\text { HAB. } / \mathrm{KM}^{2}\end{array}$ \\
\hline Braga & 183,2 & 4,15 & 164192 & 7,66 & 896,24 \\
\hline Bragança & 1173,6 & 26,56 & 34750 & 1,62 & 29,61 \\
\hline Chaves & 591,3 & 13,38 & 43667 & 2,04 & 73,85 \\
\hline Guimarães & 241,7 & 5,47 & 159576 & 7,44 & 660,22 \\
\hline Peso da Régua & 96,4 & 2,18 & 18832 & 0,88 & 195,35 \\
\hline Porto & 41,5 & 0,94 & 263131 & 12,27 & 6340,51 \\
\hline Viana do Castelo & 318,6 & 7,21 & 88631 & 4,13 & 278,19 \\
\hline Vila Nova de Gaia & 168,7 & 3,82 & 288749 & 13,47 & 1711,61 \\
\hline Vila Real & 377,1 & 8,53 & 49957 & 2,33 & 132,48 \\
\hline A Coruña & 37,6 & 0,85 & 242458 & 11,31 & 6448,35 \\
\hline Ferrol & 82,6 & 1,87 & 79520 & 3,71 & 962,71 \\
\hline Lugo & 329,8 & 7,46 & 89509 & 4,17 & 271,40 \\
\hline Monforte de Lemos & 199,5 & 4,52 & 19817 & 0,92 & 99,33 \\
\hline Ourense & 84,5 & 1,91 & 109011 & 5,08 & 1290,07 \\
\hline Pontevedra & 118,3 & 2,68 & 76798 & 3,58 & 649,18 \\
\hline Santiago de Comp. & 220,6 & 4,99 & 93273 & 4,35 & 422,82 \\
\hline Vigo & 109,1 & 2,47 & 288324 & 13,45 & 2642,75 \\
\hline Vilagarcía de Arousa & 44,2 & 1,00 & 33907 & 1,58 & 767,13 \\
\hline TOTAL & 4418,3 & 100,00 & 2144102 & 100,00 & 485,30 \\
\hline $\begin{array}{l}\text { TOTAL } \\
\text { EURORREXIÓN }\end{array}$ & 50853,00 & $8,70 \%$ & 6.372 .000 & $33,60 \%$ & 125,30 \\
\hline
\end{tabular}

Cadro 2. Municipios do Eixo Atlántico do Noroeste Peninsular

Fontes: INE (2004). Retratos territoriais, http://www.ine-pt, IGE (2004). Fichas municipais, http://www.ige.xunta.es. 


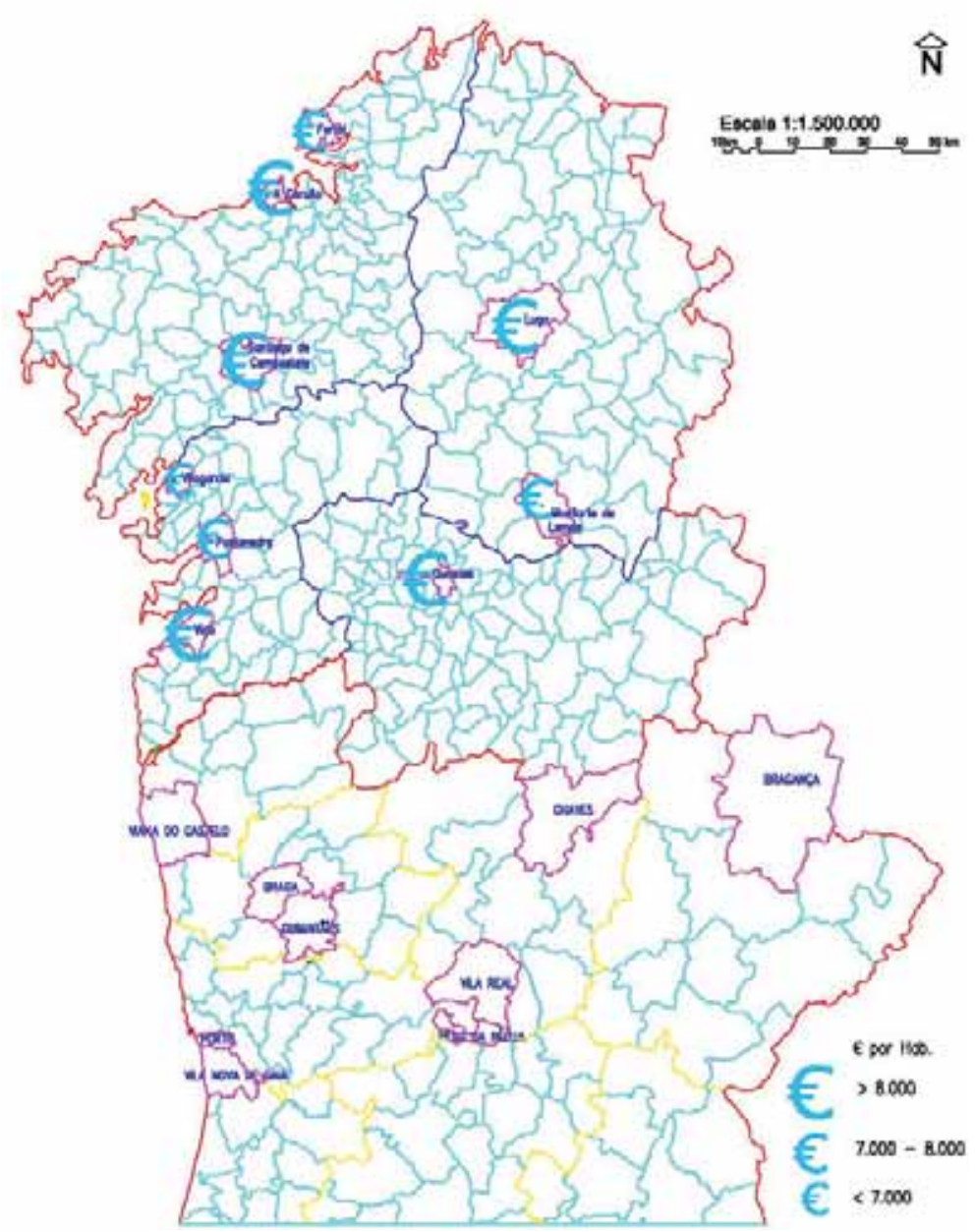

Mapa 8. Renda nas cidades do Eixo, 1996

Cunha superficie total de $4418,3 \mathrm{~km}^{2}$ (cadro 2), dos que o $55,93 \%$ se concentran nos municipios de Bragança (26,56\%), Chaves (13,38\%), Vila Real (8,53\%) e Lugo (7,46\%), esta mancomunidade de municipios ten capacidade para liderar a eurorrexión. Os seus 2144102 habitantes representan as maiores densidades poboacionais nos municipios do litoral, onde se destacan A Coruña $\left(6448,35 \mathrm{hab} . / \mathrm{km}^{2}\right)$ e Porto $(6$ $\left.340,51 \mathrm{hab} . / \mathrm{km}^{2}\right)$, mentres que as menores concentracións demográfi- 
cas ocorren no interior e nos municipios de Bragança (29,61 hab. $\left./ \mathrm{km}^{2}\right)$, Chaves (73,85 hab. $\left./ \mathrm{km}^{2}\right)$ e Monforte de Lemos (99,33 hab. $\left./ \mathrm{km}^{2}\right)$. Dinámicas socioeconómicas e administrativas, pois os municipios vanse configurar no primeiro terzo do século XIX atendendo ao poder das burguesías ascendentes.

\section{Cultura, LiNGUA, un territorio}

A avaliación que podemos facer das potencialidades deste Pacto Intermunicipal están relacionadas coa capacidade que teñan os políticos locais de convencer as súas poboacións da necesidade de complementariedade entre os concellos que conforman dita asociación intermunicipal. Unha primeira avaliación, seguindo o xa clásico modelo DAFO permite albiscar a súa potencialidade:

\begin{tabular}{|c|c|}
\hline $\begin{array}{l}\text { AMEAZAS } \\
\text { EXTERNAS }\end{array}$ & $\begin{array}{l}\text { - Cambio de situación nos Fondos Europeos de Cohesión } \\
\text { - Escasa integración no desenvolvemento europeo } \\
\text { - Situación periférica na revolución das TIC } \\
\text { - Demanda rutineira de infraestruturas }\end{array}$ \\
\hline FEBLEZAS & $\begin{array}{l}\text { - Avellentamento demográfico en Galicia } \\
\text { - Escasa colaboración intermunicipal } \\
\text { - Excesiva rixidez na burocracia estatal } \\
\text { - Excesivo uso do transporte privado } \\
\text { - Espallamento lineal do habitat periurbano }\end{array}$ \\
\hline $\begin{array}{l}\text { PUNTOS } \\
\text { FORTES }\end{array}$ & $\begin{array}{l}\text { - Paisaxe agradable, patrimonio histórico relevante } \\
\text { - Cultura inmaterial moi rica } \\
\text { - Diversidade de actividades económicas e aumento } \\
\text { dos intercambios comerciais entre Galicia e Norte de } \\
\text { Portugal. }\end{array}$ \\
\hline $\begin{array}{c}\text { OPORTUNIDADES } \\
\text { EXTERNAS }\end{array}$ & $\begin{array}{l}\text { - Novas oportunidades no espazo transfronteirizo } \\
\text { - Aumento de accesibilidade externa } \\
\text { - Integración das universidades na vida eurorrexional } \\
\text { a través de I+D na sociedade do coñecemento } \\
\text { - Accesibilidade ao tráfico marítimo internacional } \\
\text { atlántico } \\
\text { - Relacións tradicionais con Iberoamérica }\end{array}$ \\
\hline
\end{tabular}

Cadro 3. Unha primeira aproximación ás potencialidades do Eixo 
Sen dúbida na cultura material e inmaterial reside un dos alicerces da súa potencialidade. A lingua como manifestación da cultura pode tecer un tapete territorial que facilite a identidade das persoas no conxunto da eurorrexión. Iniciativas como a da asociación cultural Ponte nas Ondas, responsable da Candidatura do Patrimonio Cultural Mundial Inmaterial ante a UNESCO (presentada en París o 18 de outubro de 2004), facilitarán a expansión de tradicións, mitos e lendas que fornecen dunha cultura inmaterial ao conxunto deste espazo xeográfico, que, deste xeito, se converte nun territorio con identidade simbólica. A comunicación humana, a cartografía das expresións lingüísticas será, sen ningunha dúbida, outra das ferramentas necesarias na análise da produción cultural. 